\title{
Clinical and biochemical features of different molecular etiologies of familial chylomicronemia
}

\author{
Robert A. Hegele, MD*, Amanda J. Berberich, MD, Matthew R. Ban, BSc, \\ Jian Wang, MD, Andres Digenio, MD, Veronica J. Alexander, PhD, Laura D'Erasmo, MD, \\ Marcello Arca, MD, Alan Jones, MD, Eric Bruckert, MD, Erik S. Stroes, MD, PhD, \\ Jean Bergeron, MD, Fernando Civeira, MD, PhD, Joseph L. Witztum, MD, \\ Daniel Gaudet, MD, PhD
}

Department of Medicine, Schulich School of Medicine and Dentistry, Western University, London, Ontario, Canada (Drs Hegele and Berberich); Department of Biochemistry, Schulich School of Medicine and Dentistry, Western University, London, Ontario, Canada (Drs Hegele and Berberich); Robarts Research Institute, Western University, London, Ontario, Canada (Drs Ban and Wang); Akcea Therapeutics, Cambridge, MA, USA (Dr Digenio); Ionis Pharmaceuticals, Carlsbad, CA, USA (Dr Alexander); Department of Internal Medicine and Allied Sciences, Sapienza University of Rome, Rome, Italy (Drs D'Erasmo and Arca); Department of Clinical Biochemistry and Immunology, Heart of England NHS Foundation Trust, Birmingham, West Midlands, UK (Dr Jones); Endocrinologie Métabolisme et Prévention Cardiovasculaire, Institut E3M et IHU Cardiométabolique (ICAN), Hôpital Pitié Salpêtrière, Paris, France (Dr Bruckert); Department Vascular Medicine, Academic Medical Center, Amsterdam, The Netherlands (Dr Stroes); Départements de Médecine et de Biologie Médicale, Centre Hospitalier Universitaire de Québec-Université Laval, Québec, Canada (Dr Bergeron); Hospital Miguel Servet, IIS Aragon, CIBERCV, Universidad de Zaragoza, Spain (Dr Civeira); University of California San Diego, La Jolla, CA, USA (Dr Witztum); and Lipidology Unit, Community Genomic Medicine Centre and ECOGENE-21, Department of Medicine, Université de Montréal, Saguenay, Québec, Canada (Dr Gaudet)

KEYWORDS:

Familial chylomicronemia syndrome;

Hypertriglyceridemia;

Volanesorsen;

Lipoprotein lipase;

Lipolysis;

Genetics;

Next-generation DNA

sequencing;

Genetic variation;

Pancreatitis;
BACKGROUND: Familial chylomicronemia syndrome (FCS) is an ultra-rare phenotype that is usually caused by biallelic mutations in the $L P L$ gene encoding lipoprotein lipase, or less often in $A P O C 2$, $A P O A 5, L M F 1$, or GPIHBP1 genes encoding cofactors or interacting proteins.

OBJECTIVES: We evaluated baseline phenotypes among FCS participants in a phase 3 randomized placebo-controlled trial of volanesorsen (NCT02211209).

METHODS: Baseline clinical, fasting, and postfat load metabolic markers were assessed. Targeted next-generation DNA sequencing plus custom bioinformatics was used to genotype subjects.

RESULTS: Among 52 FCS individuals, 41 had biallelic LPL gene mutations (LPL-FCS patients): $82 \%, 7 \%$, and $11 \%$ were missense, nonsense, and splicing variants, respectively. Eleven individuals had non- $L P L$-FCS; 2 had mutations in APOA5, 5 in GPIHBP1, and 1 each in $L M F 1$ and APOC2 genes, respectively. Two other individuals were double heterozygotes, each with 1 normal $L P L$ allele. All subjects had extremely high triglycerides (TGs) and chylomicrons, but very low levels of other lipoproteins.
* Corresponding author. Robarts Research Institute, Schulich School of Medicine and Dentistry, Western University, 4288A - 1151 Richmond Street North, London, Ontario N6A 5B7, Canada.
E-mail address: hegele@ robarts.ca

Submitted February 9, 2018. Accepted for publication March 30, 2018. 
Type I

hyperlipoproteinemia
Compared with $L P L$-FCS individuals, non- $L P L$-FCS individuals were very similar for most traits, but had significantly higher postheparin LPL activity, higher 4-hour postprandial insulin and C-peptide levels; and higher low-density lipoprotein cholesterol levels. In non- $L P L$-FCS individuals compared to those with LPL-FCS, there were also nonsignificant trends toward lower levels of total and chylomicron TGs, lower 4-hour postprandial chylomicron TG levels, and higher very-low-density lipoprotein TG levels.

CONCLUSION: Thus, $L P L$ FCS and non- $L P L$ FCS are largely phenotypically similar. However, $L P L$ FCS patients have lower postheparin $L P L$ activity and a trend toward higher TGs, whereas low-density lipoprotein cholesterol was higher in non- $L P L$-FCS patients.

(C) 2018 National Lipid Association. Published by Elsevier Inc. This is an open access article under the CC BY-NC-ND license (http://creativecommons.org/licenses/by-nc-nd/4.0/).

\section{Introduction}

Familial chylomicronemia syndrome (FCS) is an extremely rare genetic condition that affects between 1 and 10 per million individuals. ${ }^{1}$ The hallmark of FCS includes severe fasting chylomicronemia, with plasma triglyceride (TG) $>1000 \mathrm{mg} / \mathrm{dL}(>11.3 \mathrm{mmol} / \mathrm{L})$, often with grossly visible lipemic serum. ${ }^{1-6}$ Chylomicrons are derived from dietary fat and under normal metabolic conditions, are rapidly cleared from the serum postprandially, generally within 3-4 hours. ${ }^{1-6}$ Clearance is largely mediated through the hydrolyzing action of lipoprotein lipase gene $(L P L)$, located on the endothelial surface of adipose and muscle tissue. ${ }^{7}$ The phenotype of FCS includes at least one physical manifestation of chylomicronemia, which include eruptive xanthoma, lipemia retinalis, pancreatitis, or hepatosplenomegaly. ${ }^{5,6}$ Although severe hypertriglyceridemia (TG $>10 \mathrm{mmol} / \mathrm{L}$ or $880 \mathrm{mg} / \mathrm{dL}$ ) is relatively common with a prevalence of $\sim 1$ in 600 in North America, only a small fraction of these individuals have FCS. . $^{1,5,6}$

FCS follows an autosomal recessive pattern of inheritance and results predominantly ( $>90 \%)$ from biallelic mutations in the $L P L$ gene encoding lipoprotein lipase $(\mathrm{LPL})^{1,5,6}$; this form we abbreviate herein as $L P L$-FCS. The remainder are caused by biallelic mutations in 4 additional genes involved in supporting or enabling LPL function, namely $A P O C 2$, APOA5, LMF1 and GPIHBP1, which encode, respectively, apolipoprotein (apo) C-II and A-V, lipase maturation factor 1 (LMF1) and glycosylphosphatidylinositol-anchored highdensity lipoprotein (HDL)-binding protein 1 (GPIHBP1), 1,5,6 and we abbreviate this group of patients as non- $L P L-F C S$. The role of each of these gene products in lipolysis of TG is discussed elsewhere. ${ }^{1,4-6}$

Given the extreme rarity of these conditions, especially of non- $L P L$-FCS, no prior studies have directly compared clinical and biochemical features of the different monogenic causes of FCS. Here, we evaluate phenotypic differences between $L P L$-FCS and non- $L P L$-FCS patients.

\section{Methods}

\section{Participants}

The study included data from clinically identified FCS participants who were screened and included in a phase 3 randomized placebo-controlled trial of volanesorsen (NCT02211209). Briefly, the trial duration was 52 weeks, and subjects were randomized $1: 1$ to receive either volanesorsen $300 \mathrm{mg}$ SC or placebo injections. The primary outcome was percent change in TG levels at 13 weeks. Inclusion criteria for the clinical trial included a personal history of pancreatitis and with documented chylomicronemia or TG values exceeding $10 \mathrm{mmol} / \mathrm{L}$ and genetic testing or postheparin lipolytic assay consistent with FCS. Patients without pancreatitis could be eligible up to a maximum of $28 \%$ of all patients. The study enrolled adult patients (age $\geq 18$ years) with a history of chylomicronemia as evidenced by documentation of lactescent serum in the fasting state, or fasting TG measurement $\geq 10 \mathrm{mmol} / \mathrm{L}(880 \mathrm{mg} / \mathrm{dL})$. The diagnosis of FCS required documentation of at least one of the following: (1) known biallelic loss-of-function mutations in $L P L$, APOC2, APOA5, GPIHBP1, or $L M F 1$ genes; (2) postheparin plasma LPL activity of $\leq 20 \%$ of normal; plus (3) fasting $\mathrm{TG} \geq 8.4 \mathrm{mmol} / \mathrm{L}(750 \mathrm{mg} / \mathrm{dL})$ at screening. Patients were willing to follow a restrictive diet ( $\leq 20 \mathrm{~g}$ fat per day). The patients included for analysis here were derived from screening our confirmatory testing on referred samples from study subjects in the clinical trial. Subjects gave informed consent for DNA sequencing, which was performed under Western University Research Ethics protocol 07920E.

\section{Clinical and biochemical assessments}

Baseline lipids, lipoproteins, apolipoproteins, and metabolic assays were performed on fasting plasma as described. ${ }^{8,9}$ Fasting venous blood samples were taken 10 minutes preintravenous and postintravenous infusion of heparin $(50 \mathrm{U} / \mathrm{kg})$, and total postheparin lipolytic activity was determined as described. ${ }^{10,11}$ A subset of markers was also examined 4 hours after liquid-formulated high-fat test meal $(4800 \mathrm{~kJ}, 130 \mathrm{~g}$ of fat, $17 \mathrm{~g}$ of protein and $21 \mathrm{~g}$ of carbohydrate).

\section{Molecular analysis}

Genomic DNA was isolated from whole blood as described. ${ }^{12}$ Genomic libraries of indexed and pooled patient samples were generated for target candidate genes in lipid metabolism. These included the coding regions, $>150$ base pairs (bp) at intron-exon boundaries and 
$>1000$ bp of the $5^{\prime}$ untranslated region of the known causative genes for monogenic chylomicronemia, including $L P L$, APOC2, APOA5, LMF1, and GPIHBP1. The targeted next-generation DNA sequencing and custom bioinformatic pipeline are known collectively as "LipidSeq". ${ }^{12,13}$ Prepared DNA libraries from each patient sample were assayed using the MiSeq personal sequencer (Illumina, San Diego, CA). The method has mean $>300$-fold coverage for each base. Sanger sequencing was used to confirm all variants.

\section{Annotation and evaluation of observed variants}

Format for storing sequence and quality files derived from the MiSeq output were processed individually using a custom-automated workflow in CLC Genomics Workbench version 8.5.1 (CLCbio, Aarhus, Denmark) for sequence alignment, variant calling, producing a variant call format file, and target region coverage statistics. Variant annotation was performed using annotation tool for genetic variants $^{14,15}$ using customized scripts (http://annovar. openbioinformatics.org/en/latest/).

There is no consensus on the procedure to attribute causality or pathogenicity to FCS variants detected by nextgeneration sequencing. Fortunately, many variants detected in monogenic chylomicronemia genes have had a long history of archiving and annotation, as well as abundant publications of functional consequences. For instance, > 150 individual variants previously reported as being causative in LPL deficiency are reported in the Human Gene Mutation Database (http://www.biobaseinternational.com/product/hgmd). ${ }^{16-18}$

Annotated coding and noncoding ( $\pm 10 \mathrm{bp}$ from adjacent exon) variants in variant call formats were first filtered to select the rare variants according to minor allele frequencies $<1 \%$ in 1000 Genomes Project $(1 \mathrm{KG}){ }^{19}$ Exome Variant Server ${ }^{20}$ or Exome Aggregation Consortium $^{21}$ databases. Polymorphism Phenotype Version $2,{ }^{22}$ Sorting Intolerant from Tolerant, ${ }^{23,24}$ and Combined Annotation Dependent Depletion ${ }^{25}$ scores were used to evaluate the deleteriousness of the filtered coding variants. Splicing-based Analysis of Variants ${ }^{26}$ and Automated Splice Site and Exon Definition Analyses ${ }^{27}$ were used to identify rare deleterious splicing variants.

Novel variants found in this study were determined to be likely causative when (1) they had no listed allele frequencies in $1 \mathrm{KG}$, Exome Variant Server or Exome Aggregation Consortium databases, no consensus genetic variant identification number in the National Center for Biotechnology Information database of single nucleotide polymorphisms, and/or were not reported in Human Gene Mutation Database or University College London familial hypercholesterolemia database; (2) for coding variants, a deleterious score for $>2$ in silico algorithms; and (3) for noncoding variants, a deleterious score for $>1$ in silico algorithm. Copy number variants, sometimes referred to as "del-dup" mutations, were determined using a custom bioinformatics approach. Hereafter, the term "mutation" is used interchangeably with "rare definite or very likely causative variant" for the sake of brevity.

As controls for our annotation pipeline, we used sequence data from the $1 \mathrm{KG}$ database. Standard criteria based on standards of the American College of Medical Genetics, and also on published functional studies where available, were used to assess the potential pathogenicity of identified mutations. Individuals with biallelic pathogenic mutations in $L P L$ were classified as " $L P L$-FCS", whereas those with pathogenic mutations in the other genes were classified as "non- $L P L$-FCS". Simple heterozygotes for loss-offunction mutations were excluded from the analysis.

\section{Statistical analysis}

Statistical analyses were conducted using SAS v9.4 (SAS Institute, Cary, NC). Between-group differences for mean quantitative traits were evaluated with Wilcoxon signed-rank test for nonparametric sample distribution, whereas differences in discrete traits were evaluated using chi-square analysis with Fisher's exact test. Statistical significance was defined as $P<.05$ for all comparisons. Our study sample afforded $84 \%$ power to detect a $50 \%$ difference in a quantitative trait whose standard deviation was $20 \%$ of the mean with 2-sided alpha $=0.05$.

\section{Results}

\section{Classification and mutation distribution}

Of 67 individuals with phenotypic data who underwent targeted next generation sequencing, 41 had likely or definitely pathogenic biallelic $L P L$ gene mutations; of these $82 \%, 7 \%$, and $11 \%$ were missense, nonsense, and splicing variants, respectively (see Supplementary Table 1). DNA quality for 1 patient from Québec was inadequate for LipidSeq; in this case, we made an exception and accepted results from the certified provincial DNA testing facility, which diagnosed homozygosity for the founder $L P L$ p.P234L loss of function variant. An additional 11 individuals had non-LPL-FCS, of whom 2 (22\%) had biallelic mutations in $A P O A 5,5(45 \%)$ had biallelic mutations in GPIHBP 1,1 (11\%) has biallelic mutations in LMF1, 1 (11\%) had biallelic mutations in $A P O C 2$, and 2 were double heterozygotes for mutations in $L P L$ and either APOA5 $(11 \%)$ or $L M F 1(11 \%)$. The remainder of individuals, with a clinical FCS phenotype, but in whom genetic testing was not fully confirmatory, were excluded from this analysis. The mutations detected in study subjects are shown in Supplementary Tables 1 and 2.

\section{Clinical and biochemical features}

Numerous clinical, demographic, and biochemical features were determined from studied individuals (Table 1). 
Non- $L P L$-FCS individuals were younger at screening than $L P L$-FCS cases $(38.3 \pm 12.3$ vs $47.1 \pm 12.8$ years, $P=.075)$. As expected, compared with $L P L$-FCS individuals, non- $L P L$-FCS individuals had significantly higher postheparin LPL activity $(39.7 \pm 29.8$ vs $6.3 \pm 5.8 \mathrm{U}$, $P=.0028)$. In addition, low-density lipoprotein (LDL) cholesterol, determined directly by ultracentrifugation, was significantly higher in individuals with non- $L P L$-FCS compared with $L P L$-FCS $(28.9 \pm 8.1 \mathrm{vs} 22.1 \pm 10.4 \mathrm{mg} /$ $\mathrm{dL}[0.57 \pm 0.27$ vs $0.75 \pm 0.21 \mathrm{mmol} / \mathrm{L}] P=.027)$, although levels in both subgroups were very low. Apo B levels were not significantly different. Finally, compared with $L P L$-FCS individuals, non- $L P L$-FCS individuals had higher postprandial insulin $(302.7 \pm 159.3$ vs $97.0 \pm 137.1 \mathrm{U} / \mathrm{L} ; P=.0089$ ) and higher postprandial Cpeptide levels $(32.5 \pm 12.3$ vs $20.7 \pm 6.2, P=.0492)$.

Compared with $L P L$-FCS individuals, non- $L P L-F C S$ individuals had a nonsignificant trend lower total (TGs) $(20.79 \pm 10.6$ vs $29.5+14.8 \mathrm{mmol} / \mathrm{L}[1840 \pm 938$ vs $2613 \pm 1307 \mathrm{mg} / \mathrm{dL}] P=.091)$, chylomicron TG

Table 1 Characteristics of molecularly characterized familial chylomicronemia subjects

\begin{tabular}{|c|c|c|c|}
\hline Clinical or biochemical feature & LPL-FCS & non-LPL-FCS & $P$-value (Wilcoxon) \\
\hline Sex (\% female) & 61.0 & 72.7 & NS \\
\hline Body mass index $\left(\mathrm{kg} / \mathrm{m}^{2}\right)$ & $24.0 \pm 5.6$ & $24.6 \pm 6.7$ & NS \\
\hline History of acute pancreatitis (\%) & 85.4 & 72.7 & NS \\
\hline Age of onset of pancreatitis (y) & $25.6 \pm 16.5$ & $27.8 \pm 8.5$ & NS \\
\hline$(\mathrm{mmol} / \mathrm{L})$ & $7.78 \pm 3.24$ & $6.27 \pm 2.23$ & \\
\hline Triglycerides (mg/dL) & $2613 \pm 1307$ & $1840 \pm 938$ & NS $(.091)$ \\
\hline$(\mathrm{mmol} / \mathrm{L})$ & $29.5 \pm 14.8$ & $20.79 \pm 10.6$ & \\
\hline LDL cholesterol (mg/dL; by ultracentrifuge) & $22.1 \pm 10.4$ & $28.9 \pm 8.1$ & .027 \\
\hline$(\mathrm{mmol} / \mathrm{L})$ & $0.57 \pm 0.27$ & $0.75 \pm 0.21$ & \\
\hline Apo A-I (mg/dL) & $92.6 \pm 13.8$ & $99.2 \pm 26.0$ & NS \\
\hline Apo B-100 (mg/dL) & $59.5 \pm 18.0$ & $60.3 \pm 13.6$ & NS \\
\hline Apo B-48 (mg/dL) & $11.4 \pm 7.11$ & $10.1 \pm 7.97$ & NS \\
\hline Apo C-III $(\mathrm{mg} / \mathrm{dL})$ & $27.4 \pm 12.1$ & $28.4 \pm 12.7$ & NS \\
\hline Chylomicron triglycerides $(\mathrm{mg} / \mathrm{dL})$ & $2296 \pm 1298$ & $1462 \pm 894$ & NS $(.060)$ \\
\hline$(\mathrm{mmol} / \mathrm{L})$ & $25.94 \pm 14.7$ & $16.52 \pm 10.1$ & \\
\hline VLDL cholesterol (mg/dL) & $31.3 \pm 26.0$ & $40.4 \pm 23.2$ & NS \\
\hline$(\mathrm{mmol} / \mathrm{L})$ & $0.81 \pm 0.67$ & $1.04 \pm 0.60$ & \\
\hline VLDL triglycerides $(\mathrm{mg} / \mathrm{dL})$ & $244.4 \pm 144.2$ & $325.9 \pm 145.7$ & NS (.059) \\
\hline$(\mathrm{mmol} / \mathrm{L})$ & $2.76 \pm 1.63$ & $3.68 \pm 1.65$ & \\
\hline Chylomicron plus VLDL apo C-III content (mg/dL) & $26.7 \pm 12.6$ & $25.6 \pm 14.2$ & NS \\
\hline$(\mathrm{mmol} / \mathrm{L})$ & $104.3 \pm 56.1$ & $68.3 \pm 51.1$ & \\
\hline Glucose $4 \mathrm{~h}$ postprandial (mg/dL) & $408.7 \pm 92.8$ & $531.6 \pm 244.1$ & NS \\
\hline$(\mathrm{mmol} / \mathrm{L})$ & $22.7 \pm 5.16$ & $29.5 \pm 13.6$ & \\
\hline Insulin $4 \mathrm{~h}$ postprandial (U/L) & $97.0 \pm 137.1$ & $302.7 \pm 159.3$ & .0089 \\
\hline C-peptide $4 \mathrm{~h}$ postprandial (U/L) & $20.7 \pm 6.2$ & $32.5 \pm 12.3$ & .0492 \\
\hline
\end{tabular}

apo, apolipoprotein; HDL, high-density lipoprotein; LDL, low-density lipoprotein; LPL-FCS, familial chylomicronemia syndrome due to biallelic mutations in the $L P L$ gene encoding lipoprotein lipase; non-LPL-FCS, familial chylomicronemia syndrome due to biallelic mutations in the either the APOC2, APOA5, LMF1, or GPIHBP1, which encode, respectively, apo C-II, apo A-V, lipase maturation factor 1, or glycosylphosphatidylinositol-anchored HDL-binding protein 1; NS, not significant; VLDL, very-low-density lipoprotein. 
$(16.52 \pm 10.1$ vs $25.94 \pm 14.7 \mathrm{mmol} / \mathrm{L}[1462 \pm 894 \mathrm{vs}$ $2296 \pm 1298 \mathrm{mg} / \mathrm{dL}] P=.060$ ), 4-hour postprandial chylomicron TGs $(68.3 \pm 51.1$ vs $104.3 \pm 56.1 \mathrm{mmol} / \mathrm{L}$ $[6045 \pm 4525$ vs $9229 \pm 4973 \mathrm{mg} / \mathrm{dL}] P=.082)$ and higher very-low-density lipoprotein (VLDL) TGs $(3.68 \pm 1.65$ vs $2.76 \pm 1.63 \mathrm{mmol} / \mathrm{L}[325.9 \pm 145.7$ vs $244.4 \pm 144.2 \mathrm{mg} / \mathrm{dL}] P=.059)$.

There were no significant differences in other measured biochemical variables, including traditional and nontraditional lipid, lipoprotein, and apolipoprotein variables. Furthermore, most variables from advanced lipoprotein analysis and from postprandial studies were similar between groups. There was no significant difference in acute pancreatitis history between non- $L P L$-FCS and $L P L$-FCS groups ( $72.7 \%$ vs $85.4 \%$, respectively) or age of first episode of pancreatitis ( $27.8 \pm 8.5$ vs $25.6 \pm 16.5$, respectively). We repeated these analyses post hoc, excluding the $L P L$ p.P234L homozygote whose diagnosis was determined by traditional sequencing only; all statistical comparisons and interpretation of results remained the same (data not shown).

\section{Discussion}

Although most patients with monogenic chylomicronemia have biallelic, loss-of-function variants in $L P L$, a substantial minority has the phenotype due to mutations in the 4 remaining minor genes. A direct head-to-head comparison of clinical and biochemical features among individuals with $L P L$-related and non- $L P L$-related monogenic chylomicronemia has not yet been reported, generally because these patients are so rare, and consistent harmonized methods have not been used in a larger cohort of individuals. Here, because of the comprehensive assessments of these individuals due to their involvement in a clinical trial, we had a unique collection of phenotypically and genotypically well-characterized individuals with monogenic chylomicronemia to allow for a detailed assessment of phenotypic differences according to the main underlying molecular classes.

Our findings primarily indicate that for most fasting and dynamic metabolic measures, individuals with monogenic chylomicronemia are phenotypically similar whether the underlying cause is biallelic mutations in $L P L$ or one of the other 4 genes. The difference in postheparin LPL activity was expected based on our understanding of the biochemistry and genetic basis of the different forms of the condition. Individuals with mutations in non- $L P L$ genes, by definition, had normal LPL enzyme, and thus, there would be less expected lipolytic compromise under the conditions of the ex vivo lipolytic assay. We note in Supplementary Table 3 that ex vivo lipolysis is lower in patients with $L M F 1$ and $G P I H B P 1$ mutations than in the other non- $L P L$-FCS genetic subgroups, but not as low as for $L P L$-FCS patients. Under in vitro conditions, the deficiencies resulting from $L M F 1$ and GPIHBP1 mutations that would otherwise impair in vivo function become less relevant. Similarly, the deficiencies resulting from mutations in APOA5 and APOC2 can be rescued because the in vitro test substrate contains some normal apolipoproteins. Thus, on balance, non- $L P L$ mutation patients had higher LPL activity. The trend toward significantly higher levels of chylomicrons and TGs seen in $L P L$-mutation positive patients suggests that LPL deficiency may manifest with somewhat more severe chylomicronemia than FCS resulting from mutations in non- $L P L$ genes.

Of particular note, total cholesterol values were high in both groups, whereas LDL, HDL, VLDL cholesterol levels were all low in both $L P L$-FCS and non- $L P L$-FCS groups. This highlights a fundamental feature of the metabolic defect in FCS. With absent or minimal LPL activity, there is a significant impairment in conversion of TG-rich particles to their remnant lipoproteins, which generates a cascading impairment in production of subsequent smaller lipoprotein subfractions, for which these remnants are the initial substrate. Each step of the lipoprotein metabolism pathway involves lipolysis of TG via LPL for conversion to a smaller lipoprotein species (ie, from chylomicrons to chylomicron remnants to VLDL to VLDL remnants and intermediate density lipoprotein to LDL). Although LPL-deficient individuals commonly exhibit elevated total cholesterol values, the cholesterol measured is predominantly present within chylomicrons, with a TG to cholesterol ratio of $\sim 20: 1$, with VLDL, intermediate density lipoprotein and LDL cholesterol all typically at very low levels. HDL cholesterol is similarly low due to a decrease in available cholesterol from its primary sources: VLDL, LDL, and peripheral tissues. This does not hold true, however, for individuals with other secondary or polygenic causes of elevated TGs, in which LPL is generally functional, and all lipoproteins and their remnants can be present and elevated to varying degrees, along with an increase in cardiovascular risk. This key concept has significant implications when selecting appropriate therapy. Although secondary and polygenic (type V) hypertriglyceridemia patients who have some residual LPL activity can often be effectively managed with fibrates or other oral agents, this is not expected to be effective in patients with LPL deficiency, who require more targeted TG-specific therapy.

Further subdividing the non- $L P L$-FCS subgroup by genotype allows for some additional anecdotal observations (see Supplementary Table 3). For instance, in the LMF1-deficient patient, plasma apo A-I is very high, consistent with a concomitant low hepatic lipase activity affecting apo A-Icontaining particles, as would be expected given the role of LMF1 in maturation of both lipases. Although in this patient, there is no obvious difference in baseline LDL and HDL cholesterol levels, it is notable that total and especially postprandial TGs are very high. Furthermore, the TG levels in the APOC2- and APOA5-deficient patients appear somewhat lower than in the $L P L$-FCS group, as might be expected. In addition, the apo C-III content of various particles does not appear to differ between genotypes. Finally, the double heterozygotes who each have 1 normal functioning $L P L$ allele have, as expected, the lowest TG levels at baseline and especially postprandially.

The significantly higher level of LDL cholesterol seen in patients with non-LPL-FCS compared with the LPL-FCS 
population has not been previously described. It may reflect a less severe impairment of LPL activity in these patients, or the presence of concomitant secondary causes, compared with the $L P L$-FCS group. It may also suggest a minor or indirect role of APOC2, APOA5, LMF1, or GPIHBP1 in LDL processing or clearance, or potentially the clustering of other unmeasured risk genes in this subgroup compared with those with $L P L$-FCS. Some support for this may come from studies that have shown an association between mutations in APOA5 and APOC2 and hypercholesterolemia. ${ }^{28}$ Environmental, or gene-environment interactions, may also be playing a role. Interestingly apo B levels were not significantly different between the 2 groups, although specific B-100 and B-48 assays were not performed. Further investigation is required to fully mechanistically define such potential differences.

The tendency of non- $L P L$ mutation carriers to have somewhat worse indices of insulin resistance suggests that this secondary factor may be playing an underlying role in this subgroup. Alternatively, perhaps the $L P L$ defect leads to greater requirements for glucose in peripheral tissues with improved insulin sensitivity and lower glucose levels, assuming the islets are functioning normally. In addition, some of the non- $L P L$ gene product mechanisms may be predisposing to somewhat compromised insulin sensitivity, in addition to their major effects on chylomicron and lipoprotein metabolism. However, the similarity of the remainder of the phenotypes suggests that regardless of etiology, large effect mutations directly affecting $L P L$ or one of its critical interacting factors results in a severe phenotype that is clinically and biochemically similar irrespective of the molecular etiology. It would be important to rigorously evaluate insulin sensitivity in individuals subdivided according to FCS genotype class.

The pancreatitis rates were high in both groups $(75 \%$ and $85 \%$, respectively); however, it is important to note that this was as a result of the clinical trial selection criteria, which included a personal history of pancreatitis, and should not be misinterpreted as prevalence rates for pancreatitis in either genotype.

\section{Limitations}

Even though we have collected a unique and relatively large group of these extremely rare individuals, the sample size is small, and it is possible that more subtle differences in some of these variables would be apparent with a larger number of subjects, particularly those with non- $L P L$ monogenic chylomicronemia. Furthermore, we did not have sufficient numbers of individuals to further subdivide according to minor gene etiology or mutation type. Because these individuals were studied in a trial of an inhibitor of apo C-III, it would have been informative to have collected not just apo C-III content in subfractions but also apo $\mathrm{E}$ and apo A-V, however, these were not available. We note that apo C-III content was available in TGrich particles (chylomicrons plus VLDL) and also in HDL; overall, these were not statistically different between the genotypic classes.

In addition, it is important to note that the trial inclusion criteria limited this data analysis to relatively severe cases of chylomicronemia. This has the potential to miss important differences between $L P L$-FCS and non- $L P L$ FCS that may have been seen if those with milder phenotypes were included. It is also important to note that different mutations in both $L P L$ and non- $L P L$ genes could present with a wide phenotypic spectrum based on the severity of functional compromise that results from a given mutation. We also excluded heterozygous $L P L$ mutationpositive patients from analysis; however, it is possible that heterozygous null mutation carriers may present with a phenotype that overlaps with milder homozygous or compound heterozygous mutation-positive individuals and further analysis based on degree of functional compromise could be informative. Finally, it might also have been informative to examine the individuals with a clinical FCS phenotype but in whom genetic testing or LPL activity were not fully confirmatory, although such patients would not be easily classified in this experimental design.

\section{Future directions}

This study compared phenotypes of the individuals tested who presented with a clinical FCS phenotype and had a confirmed genetic basis for their severe chylomicronemia. It is possible that the remaining individuals have as-yet unidentified mutations causing true FCS, or they may simply have severe secondary or polygenic (type V) chylomicronemia. The features of these 15 individuals were not compared with those who had confirmatory genetic testing in our study. For some lipidologists, the diagnosis of FCS should include genetic testing, although the ability to make a diagnosis based on predictive clinical features alone is highly attractive. It is beyond the scope of this study to recommend the necessity for genetic testing to diagnose patients with true biallelic FCS from among the multitude of those with severe hypertriglyceridemia. However, once genetic testing has been performed, and individuals with FCS are subdivided between biallelic $L P L$ and non- $L P L$ subgroups, the betweengenotype clinical and biochemical differences are subtle. A comparison between individuals with a clinical FCS phenotype but no genetic diagnosis to those who have identified mutations could be informative. Some preliminary work suggests that some predictive features may include a personal history of pancreatitis, low body mass index and low apo B levels (unpublished data).

In summary, we found that patients with $L P L$-related and non- $L P L$-related monogenic chylomicronemia are largely phenotypically similar, but that $L P L$-FCS has lower postheparin LPL activity and somewhat higher chylomicrons and TGs, whereas LDL cholesterol was higher in non- $L P L$-FCS. It remains to be determined whether these 2 subgroups of patients differ with respect to other attributes, including the response to interventions. 


\section{Acknowledgments}

R.A.H. has received operating grants from the Canadian Institutes of Health Research (Foundation Grant), the Heart and Stroke Foundation of Ontario (G-15-0009214), and Genome Canada through Genome Quebec (award 4530). A.J.B. is supported by the Clinical Investigator Program at the Schulich School of Medicine \& Dentistry, Western University and by the Fernand Labrie Fellowship of the Canadian Society for Endocrinology. D.G. team received support from the ECOGENE21 biocluster. The authors would like to thank all study participants.

Authors' contribution: R.A.H. conceived and planned the study with A.D. and J.L.W. R.A.H., A.D., V.J.A., L.D.E., M.A., A.J., E.B., E.S.S., J.B., F.C., J.L.W., and D.G. provided patient data. R.A.H., A.J.B., M.R.B., J.W., A.D., and V.J.A. analyzed the data. R.A.H., A.J.B., A.D., and J.L.W. drafted the article. All authors reviewed, provided comments, and approved the final version of the article.

\section{Financial disclosure}

R.A.H. has received honoraria for membership on advisory boards and speakers' bureaus for Akcea/Ionis, Aegerion, Amgen, Gemphire, Regeneron, Sanofi, and Valeant. F.C. has received honoraria for membership on advisory boards and speakers' bureaus for Amgen, Sanofi, Merck, and Ferrer. J.B. has received honoraria for membership on advisory boards of Akcea/Ionis, Amgen, Sanofi, and speakers' bureaus for Amgen and Sanofi. D.G. has received research grants, honoraria as consultant or for participating in advisory boards for Ionis, Aegerion, Amgen, Arrowhead, Chiesi, Gemphire, Nestle, Regeneron, Sanofi, and Uniqure. J.L.W. is a consultant for Ionis Pharmaceutical.

\section{References}

1. Johansen CT, Kathiresan S, Hegele RA. Genetic determinants of plasma triglycerides. J Lipid Res. 2011;52:189-206.

2. Yuan G, Al-Shali KZ, Hegele RA. Hypertriglyceridemia: its etiology, effects and treatment. CMAJ. 2007;176:1113-1120.

3. Rahalkar AR, Hegele RA. Monogenic pediatric dyslipidemias: classification, genetics and clinical spectrum. Mol Genet Metab. 2008;93: 282-294.

4. Hegele RA. Plasma lipoproteins: genetic influences and clinical implications. Nat Rev Genet. 2009;10:109-121.

5. Brahm A, Hegele RA. Hypertriglyceridemia. Nutrients. 2013;5: 981-1001.

6. Brahm AJ, Hegele RA. Chylomicronaemia-current diagnosis and future therapies. Nat Rev Endocrinol. 2015;11:352-362.

7. Mendoza-Barbera E, Julve J, Nilsson SK, et al. Structural and functional analysis of APOA5 mutations identified in patients with severe hypertriglyceridemia. J Lipid Res. 2013;54:649-661.

8. Gaudet D, Brisson D, Tremblay K, et al. Targeting APOC3 in the familial chylomicronemia syndrome. N Engl J Med. 2014;371: 2200-2206.

9. Gaudet D, Alexander VJ, Baker BF, et al. Antisense inhibition of apolipoprotein C-III in patients with hypertriglyceridemia. $N$ Engl $J$ Med. 2015;373:438-447.
10. Di Filippo M, Marcais C, Charriere S, et al. Post-heparin LPL activity measurement using VLDL as a substrate: a new robust method for routine assessment of plasma triglyceride lipolysis defects. PLOS One. 2014;9:e96482.

11. Marmontel O, Di Filippo M, Marcais C, et al. Alterations in plasma triglycerides lipolysis in patients with history of multifactorial chylomicronemia. Atherosclerosis. 2017;265:22-28.

12. Johansen CT, Dube JB, Loyzer MN, et al. LipidSeq: a next-generation clinical resequencing panel for monogenic dyslipidemias. J Lipid Res. 2014;55:765-772.

13. Hegele RA, Ban MR, Cao H, McIntyre AD, Robinson JF, Wang J. Targeted next-generation sequencing in monogenic dyslipidemias. Curr Opin Lipidol. 2015;26:103-113.

14. Wang K, Li M, Hakonarson H. ANNOVAR: functional annotation of genetic variants from high-throughput sequencing data. Nucleic Acids Res. 2010;38:e164.

15. Yang $\mathrm{H}$, Wang $\mathrm{K}$. Genomic variant annotation and prioritization with ANNOVAR and wANNOVAR. Nat Protoc. 2015;10:1556-1566.

16. Wishart DS, Jewison T, Guo AC, et al. HMDB 3.0-The Human Metabolome Database in 2013. Nucleic Acids Res. 2013;41:D801-807.

17. Wishart DS, Knox C, Guo AC, et al. HMDB: a knowledgebase for the human metabolome. Nucleic Acids Res. 2009;37:D603-610.

18. Wishart DS, Tzur D, Knox C, et al. HMDB: the human metabolome database. Nucleic Acids Res. 2007;35:D521-526.

19. Auton A, Brooks LD, Durbin RM, et al, 1000 Genomes Project Consortium. A global reference for human genetic variation. Nature. 2015; 526:68-74.

20. Seattle, WAExome Variant Server, NHLBI GO Exome Sequencing Project (ESP). 2017Available at: https://eps.gs.washington.eud/ drupal/.

21. Lek M, Karczewski KJ, Minikel EV, et al. Analysis of protein-coding genetic variation in 60,706 humans. Nature. 2016;536:285-291.

22. Adzhubei IA, Schmidt S, Peshkin L, et al. A method and server for predicting damaging missense mutations. Nat Methods. 2010;7: 248-249.

23. Kumar P, Henikoff S, Ng PC. Predicting the effects of coding nonsynonymous variants on protein function using the SIFT algorithm. Nat Protoc. 2009;4:1073-1081.

24. Ng PC, Henikoff S. SIFT: Predicting amino acid changes that affect protein function. Nucleic Acids Res. 2003;31:3812-3814.

25. Kircher M, Witten DM, Jain P, O'Roak BJ, Cooper GM, Shendure J. A general framework for estimating the relative pathogenicity of human genetic variants. Nat Genet. 2014;46:310-315.

26. Xiong HY, Alipanahi B, Lee LJ, et al. RNA splicing. The human splicing code reveals new insights into the genetic determinants of disease. Science. 2015;347:1254806.

27. Mucaki EJ, Shirley BC, Rogan PK. Prediction of mutant mRNA splice isoforms by information theory-based exon definition. Hum Mutat. 2013;34:557-565.

28. Paththinige CS, Sirisena ND, Dissanayake V. Genetic determinants of inherited susceptibility to hypercholesterolemia - a comprehensive literature review. Lipids Health Dis. 2017;16:103.

29. Ma Y, Henderson HE, Murthy V, et al. A mutation in the human lipoprotein lipase gene as the most common cause of familial chylomicronemia in French Canadians. N Engl J Med. 1991;324:1761-1766.

30. Sacks FM, Stanesa M, Hegele RA. Severe hypertriglyceridemia with pancreatitis: thirteen years' treatment with lomitapide. JAMA Intern Med. 2014;174:443-447.

31. Emi M, Wilson DE, Iverius PH, et al. Missense mutation (GlyGlu188) of human lipoprotein lipase imparting functional deficiency. J Biol Chem. 1990;265:5910-5916.

32. Ashraf AP, Hurst ACE, Garg A. Extreme hypertriglyceridemia, pseudohyponatremia, and pseudoacidosis in a neonate with lipoprotein lipase deficiency due to segmental uniparental disomy. J Clin Lipidol. 2017; 11:757-762.

33. Bordugo A, Carlin E, Demarini S, Faletra F, Colonna F. A neonate with a 'milky' blood. What can it be? Arch Dis Child Fetal Neonatal Ed. 2014;99:F514. 
34. Ma Y, Wilson BI, Bijvoet S, et al. A missense mutation (Asp250Asn) in exon 6 of the human lipoprotein lipase gene causes chylomicronemia in patients of different ancestries. Genomics. 1992;13: 649-653.

35. Bertolini S, Simone ML, Pes GM, et al. Pseudodominance of lipoprotein lipase (LPL) deficiency due to a nonsense mutation (Tyr302> Term) in exon 6 of LPL gene in an Italian family from Sardinia (LPL(Olbia)). Clin Genet. 2000;57:140-147.

36. Henderson HE, Ma Y, Hassan MF, et al. Amino acid substitution (Ile194-Thr) in exon 5 of the lipoprotein lipase gene causes lipoprotein lipase deficiency in three unrelated probands. Support for a multicentric origin. J Clin Invest. 1991;87:2005-2011.

37. Ooi EM, Russell BS, Olson E, et al. Apolipoprotein B-100-containing lipoprotein metabolism in subjects with lipoprotein lipase gene mutations. Arterioscler Thromb Vasc Biol. 2012; 32:459-466.

38. Bijvoet SM, Bruin T, Tuzgol S, Bakker HD, Hayden MR, Kastelein JJ. Homozygosity for a mutation in the lipoprotein lipase gene (Gly139->Ser) causes chylomicronaemia in a boy of Spanish descent. Hum Genet. 1994;93:339-343.

39. Ishimura-Oka K, Faustinella F, Kihara S, Smith LC, Oka K, Chan L. A missense mutation (Trp86-Arg) in exon 3 of the lipoprotein lipase gene: a cause of familial chylomicronemia. Am J Hum Genet. 1992; 50:1275-1280

40. Surendran RP, Visser ME, Heemelaar S, et al. Mutations in LPL, APOC2, APOA5, GPIHBP1 and LMF1 in patients with severe hypertriglyceridaemia. J Intern Med. 2012;272:185-196.
41. Gotoda T, Yamada N, Kawamura M, et al. Heterogeneous mutations in the human lipoprotein lipase gene in patients with familial lipoprotein lipase deficiency. J Clin Invest. 1991;88:1856-1864.

42. Behar DM, Adler L, Basel-Vanagaite L. Severe hypertriglyceridemia in an infant of Arab descent. Isr Med Assoc J. 2013;15:53-54.

43. Mailly F, Palmen J, Muller DP, et al. Familial lipoprotein lipase (LPL) deficiency: a catalogue of LPL gene mutations identified in 20 patients from the UK, Sweden, and Italy. Hum Mutat. 1997;10:465-473.

44. Rabacchi C, Pisciotta L, Cefalu AB, et al. Spectrum of mutations of the LPL gene identified in Italy in patients with severe hypertriglyceridemia. Atherosclerosis. 2015;241:79-86.

45. Reina M, Brunzell JD, Deeb SS. Molecular basis of familial chylomicronemia: mutations in the lipoprotein lipase and apolipoprotein C-II genes. J Lipid Res. 1992;33:1823-1832.

46. Stefanutti C, Gozzer M, Pisciotta L, et al. A three month-old infant with severe hyperchylomicronemia: molecular diagnosis and extracorporeal treatment. Atheroscler Suppl. 2013;14:73-76.

47. Bruin T, Tuzgol S, Mulder WJ, et al. A compound heterozygote for lipoprotein lipase deficiency, Val69->Leu and Gly188-> Glu: correlation between in vitro LPL activity and clinical expression. $J$ Lipid Res. 1994;35:438-445.

48. Pisciotta L, Fresa R, Bellocchio A, et al. Two novel rare variants of APOA5 gene found in subjects with severe hypertriglyceridemia. Clin Chim Acta. 2011;412:2194-2198.

49. Berge KE, Retterstol K, Romeo S, Pirazzi C, Leren TP. Type 1 hyperlipoproteinemia due to a novel deletion of exons 3 and 4 in the GPIHBP1 gene. Atherosclerosis. 2014;234:30-33. 


\section{Appendix}

Supplementary Table 1 Lipoprotein lipase gene $(L P L)$ mutation status and LPL activity

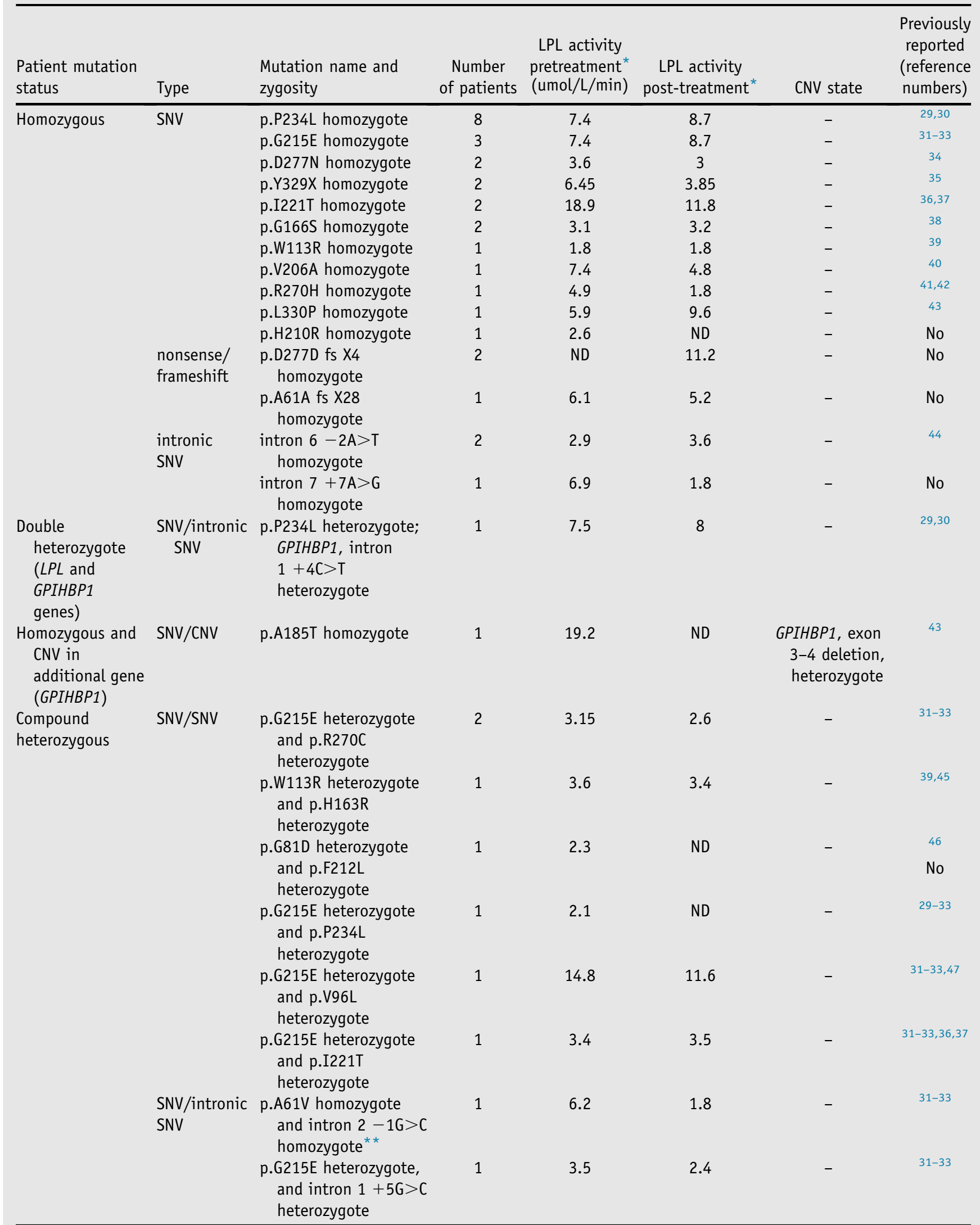

\footnotetext{
LPL, lipoprotein lipase; SNV, single nucleotide variant; CNV, copy number variant; ND, not determined; -, absent.

${ }^{*}$ Average taken if data available for more than one patient with mutation.

${ }^{* *}$ Individual is a complex homozygote for both a missense SNV and intronic variant, which each may be pathogenic.
} 
Supplementary Table 2 Non-lipoprotein lipase gene (non- $L P L$ ) mutation status and LPL activity

\begin{tabular}{|c|c|c|c|c|c|}
\hline Gene & Mutation & CNV state & $\begin{array}{l}\text { LPL activity } \\
\text { pretreatment* }^{*} \\
\text { (umol/L/min) }\end{array}$ & $\begin{array}{c}\text { LPL activity } \\
\text { post-treatment* }\end{array}$ & $\begin{array}{l}\text { Previously } \\
\text { reported? }\end{array}$ \\
\hline \multirow[t]{2}{*}{ APOA5 } & $\begin{array}{l}\text { p.Q3300 fs X6 } \\
\text { homozygote }\end{array}$ & - & 37 & 4 & No \\
\hline & p.L253P homozygote & - & 56.4 & - & 7,48 \\
\hline APOC2 & $\begin{array}{l}\text { intron } 3+1 \mathrm{G}>\mathrm{C} \\
\text { homozygote }\end{array}$ & $\begin{array}{l}\text { APOC2, exon } \\
1 \text { deletion } \\
\text { (noncoding), } \\
\text { homozygote }\end{array}$ & 80 & - & No \\
\hline LMF1 & p.P248S homozygote & - & 31.7 & 13.5 & No \\
\hline \multirow[t]{2}{*}{ GPIHBP1 } & p.A6D homozygote & - & 16.1 & 14.6 & No \\
\hline & p.Q132X homozygote & - & - & 4.6 & No \\
\hline \multirow[t]{2}{*}{$\begin{array}{l}\text { Double } \\
\text { heterozygote } \\
L P L+\text { other }\end{array}$} & $\begin{array}{l}\text { LPL p.G215E } \\
\text { heterozygote; } \\
\text { APOA5 p.A315V } \\
\text { heterozygote }\end{array}$ & - & 80 & - & $\begin{array}{l}31-33 \\
\text { No }\end{array}$ \\
\hline & $\begin{array}{l}\text { LPL p.R1160 } \\
\text { heterozygote; LMF1 } \\
\text { p.R233X } \\
\text { heterozygote }\end{array}$ & - & - & - & $\begin{array}{l}44 \\
\text { No }\end{array}$ \\
\hline \multirow[t]{2}{*}{ CNV } & - & $\begin{array}{l}\text { GPIHBP1, deletion, homozygote } \\
\text { GPIHBP1, exon } \\
\text { 3-4 deletion, homozygote }\end{array}$ & $\begin{array}{c}1.8 \\
14.9\end{array}$ & $\begin{array}{c}- \\
17.3\end{array}$ & $\mathrm{No}_{7}$ \\
\hline & - & $\begin{array}{c}\text { GPIHBP1, exon } \\
\text { 3-4 deletion, homozygote }\end{array}$ & - & 3.9 & 49 \\
\hline
\end{tabular}

LPL, lipoprotein lipase; SNV, single nucleotide variant; CNV, copy number variant; ND, not determined; -, absent.

*Average taken if data available for more than one patient with the genotype. 
Supplementary Table 3 Characteristics of molecularly characterized familial chylomicronemia subjects

\begin{tabular}{|c|c|c|c|c|c|c|c|}
\hline $\begin{array}{l}\text { Clinical or } \\
\text { biochemical feature }\end{array}$ & $L P L$ & APOC2 & APOA5 & LMF1 & GPIHBP1 & $\begin{array}{c}\text { Double } \\
\text { heterozygote }\end{array}$ & $\begin{array}{c}P \text {-value } \\
\text { (overall) }\end{array}$ \\
\hline Number of individuals & 41 & 1 & 2 & 1 & 5 & 2 & - \\
\hline Sex (\% female) & 61.0 & 100.0 & 100.0 & 100.0 & 60.0 & 50.0 & NS \\
\hline Age at screening & $47.1 \pm 12.8$ & 56 & $46.5 \pm 6.4$ & 39 & $33.8 \pm 11.9$ & $32.0 \pm 17.0$ & NS \\
\hline $\begin{array}{l}\text { Body mass index } \\
\left(\mathrm{kg} / \mathrm{m}^{2}\right)\end{array}$ & $24.0 \pm 5.6$ & 20.5 & $23.6 \pm 1.98$ & 17.9 & $22.4 \pm 4.21$ & $36.2 \pm 3.39$ & .045 \\
\hline History of acute pancreatitis (\%) & 85.4 & 100.0 & 50.0 & 100.0 & 60.0 & 100.0 & NS \\
\hline Age of onset of pancreatitis (y) & $25.6 \pm 16.5$ & 41 & 26.0 & 24.0 & $24.3 \pm 6.03$ & $29.0 \pm 14.1$ & NS \\
\hline Postheparin LPL activity at baseline ( $\mu \mathrm{mol} / \mathrm{L} / \mathrm{min})$ & $6.3 \pm 5.8$ & 80.0 & $46.7 \pm 13.7$ & 31.7 & $10.9 \pm 7.93$ & 80.0 & $<.0001$ \\
\hline Total cholesterol $(\mathrm{mg} / \mathrm{dL})$ & $300.9 \pm 125.4$ & 188 & $246.5 \pm 143.5$ & 362 & $254.8 \pm 53.9$ & $175.5 \pm 122.3$ & NS \\
\hline (mmol/L) & $7.78 \pm 3.24$ & 4.86 & $6.37 \pm 3.71$ & 9.36 & $6.59 \pm 1.39$ & $4.53 \pm 3.16$ & \\
\hline Triglycerides (mg/dL) & $2613 \pm 1307$ & 1254 & $1969 \pm 1790$ & 2683 & $2096 \pm 627.3$ & $944 \pm 1001$ & NS \\
\hline$(\mathrm{mmol} / \mathrm{L})$ & $29.5 \pm 14.8$ & 14.2 & $22.2 \pm 20.2$ & 30.3 & $23.7 \pm 7.08$ & $10.7 \pm 11.3$ & \\
\hline LDL cholesterol (mg/dL; by ultracentrifuge) & $22.1 \pm 10.2$ & 28 & $30.5 \pm 10.6$ & 20 & $27 \pm 7.81$ & $37 \pm 8.49$ & NS \\
\hline (mmol/L) & $0.57 \pm 0.26$ & 0.72 & $0.79 \pm 0.27$ & 0.52 & $0.70 \pm 0.20$ & $0.96 \pm 0.22$ & \\
\hline HDL cholesterol (mg/dL; by precipitation) & $15.2 \pm 4.1$ & 14 & 18 & 18 & $13.6 \pm 1.67$ & $18.5 \pm 6.36$ & NS \\
\hline (mmol/L) & $0.39 \pm 0.11$ & 0.36 & 0.47 & 0.47 & $0.35 \pm 0.043$ & $0.48 \pm 0.16$ & \\
\hline Non-HDL cholesterol (mg/dL) & $284.9 \pm 124.6$ & 174 & $228.5 \pm 143.5$ & 344 & $241.2 \pm 53.4$ & $157 \pm 128.7$ & NS \\
\hline$(\mathrm{mmol} / \mathrm{L})$ & $7.36 \pm 3.22$ & 4.50 & $5.91 \pm 3.71$ & 8.90 & $6.24 \pm 1.38$ & $4.06 \pm 3.33$ & \\
\hline Apo A-I (mg/dL) & $92.6 \pm 13.8$ & 79 & $136 \pm 11.3$ & 140 & $85.8 \pm 12.3$ & $85.5 \pm 0.71$ & $<.0001$ \\
\hline Apo B-100 (mg/dL) & $59.5 \pm 18.0$ & 55 & $69.15 \pm 2.62$ & 66.3 & $52.6 \pm 13.2$ & $70.6 \pm 20.3$ & NS \\
\hline Apo B-48 (mg/dL) & $11.4 \pm 7.11$ & 4.88 & $3.62 \pm 2.73$ & 18.1 & $14.3 \pm 8.21$ & $4.5 \pm 5.62$ & NS \\
\hline Apo C-III (mg/dL) & $27.4 \pm 12.1$ & 19.39 & $31.9 \pm 11.8$ & 38.6 & $25.9 \pm 11.1$ & $30.6 \pm 27.1$ & NS \\
\hline Chylomicron triglycerides $(\mathrm{mg} / \mathrm{dL})$ & $2296 \pm 1298$ & 959 & $1551 \pm 1730$ & 2123 & $1780 \pm 624.2$ & $501.5 \pm 623$ & NS \\
\hline$(\mathrm{mmol} / \mathrm{L})$ & $25.94 \pm 14.7$ & 10.8 & $17.5 \pm 19.5$ & 24.0 & $20.1 \pm 7.05$ & $5.66 \pm 7.03$ & \\
\hline VLDL cholesterol (mg/dL) & $31.3 \pm 26.0$ & 28 & $36.5 \pm 3.54$ & 67 & $34.2 \pm 10.4$ & $49.5 \pm 57.3$ & NS \\
\hline$(\mathrm{mmol} / \mathrm{L})$ & $0.81 \pm 0.67$ & 0.72 & $0.94 \pm 0.092$ & 0.76 & $0.88 \pm 0.27$ & $1.28 \pm 1.48$ & \\
\hline VLDL triglycerides (mg/dL) & $244.4 \pm 144.2$ & 238 & $312 \pm 1.41$ & 449 & $290 \pm 95.5$ & $394 \pm 355$ & NS \\
\hline$(\mathrm{mmol} / \mathrm{L})$ & $2.76 \pm 1.63$ & 2.69 & $3.52 \pm 0.016$ & 5.07 & $3.27 \pm 1.08$ & $4.45 \pm 4.01$ & \\
\hline Chylomicron plus VLDL apo C-III content (mg/dL) & $26.7 \pm 12.6$ & - & - & - & $24.4 \pm 11.05$ & $28.5 \pm 26.5$ & NS \\
\hline HDL apo C-III content (mg/dL) & $1.26 \pm 0.56$ & 0.92 & - & - & $1.15 \pm 0.50$ & $1.09 \pm 0.071$ & NS \\
\hline Glucose $(\mathrm{mg} / \mathrm{dL})$ & $93.7 \pm 13.8$ & 79.0 & $93.5 \pm 3.54$ & 167 & $90.0 \pm 5.5$ & $105 \pm 4.24$ & $<.0001$ \\
\hline$(\mathrm{mmol} / \mathrm{L})$ & $5.21 \pm 0.77$ & 4.39 & $5.19 \pm 0.20$ & 9.28 & $5 \pm 0.31$ & $5.83 \pm 0.24$ & \\
\hline Triglycerides $4 \mathrm{~h}$ postprandial (mg/dL) & $10031 \pm 5125$ & 7706 & $6124 \pm 4019$ & 18173 & $7042 \pm 3090$ & 1331 & NS \\
\hline$(\mathrm{mmol} / \mathrm{L})$ & $113.3 \pm 57.9$ & 87.0 & $69.1 \pm 45.4$ & 205.2 & $79.5 \pm 34.9$ & 15.0 & \\
\hline Apo B-48 4 h post-prandial (mg/dL) & $41.08 \pm 23.09$ & 42.1 & $29.4 \pm 28.1$ & 114.52 & $29.2 \pm 13.7$ & 3.87 & .021 \\
\hline
\end{tabular}




\begin{tabular}{|c|c|c|c|c|c|c|c|}
\hline Chylomicron triglycerides $4 \mathrm{~h}$ postprandial (mg/dL) & $9229 \pm 4973$ & 6473.5 & $4396 \pm 3650$ & 15685 & $5784 \pm 3250$ & 583.5 & NS \\
\hline$(\mathrm{mmol} / \mathrm{L})$ & $104.3 \pm 56.1$ & 73.09 & $49.6 \pm 41.2$ & 177.1 & $65.3 \pm 36.7$ & 6.59 & \\
\hline Glucose $4 \mathrm{~h}$ postprandial (mg/dL) & $408.7 \pm 92.8$ & & 420.5 & 943 & $365 \pm 15.6$ & 564.5 & .0003 \\
\hline$(\mathrm{mmol} / \mathrm{L})$ & $22.7 \pm 5.16$ & & 23.4 & 52.4 & $20.3 \pm 0.87$ & 31.4 & \\
\hline Insulin $4 \mathrm{~h}$ postprandial $(\mathrm{U} / \mathrm{L})$ & $97.0 \pm 137.1$ & - & 413.2 & 527.4 & $177.9 \pm 16.1$ & 216.8 & .022 \\
\hline C-peptide $4 \mathrm{~h}$ postprandial (U/L) & $20.7 \pm 6.1$ & - & 38.1 & 49.1 & $27.7 \pm 9.95$ & 20.0 & .0015 \\
\hline
\end{tabular}

Apo, apolipoprotein; HDL, high-density lipoprotein; LDL, low-density lipoprotein; LPL-FCS, familial chylomicronemia syndrome due to biallelic mutations in the $L P L$ gene encoding lipoprotein lipase; non-

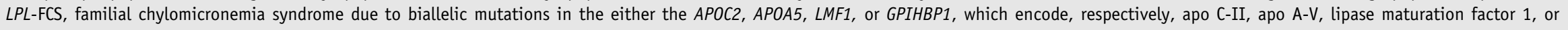
glycosylphosphatidylinositol-anchored HDL-binding protein 1; NS, not significant; VLDL, very-low-density lipoprotein.

$P$-values calculated from analysis of variance and indicates an overall difference between classes. Pairwise comparisons between individual classes were not performed. 